\title{
Effects of Abies sibirica terpenes on cancer- and aging- associated pathways in human cells
}

\author{
Anna Kudryavtseva ${ }^{1,2, *}$, George Krasnov ${ }^{1, *}$, Anastasiya Lipatova1, Boris Alekseev ${ }^{2}$, \\ Faniya Maganova ${ }^{3}$, Mikhail Shaposhnikov ${ }^{4}$, Maria Fedorova ${ }^{1}$, Anastasiya \\ Snezhkina ${ }^{1}$, Alexey Moskalev ${ }^{1,4,5}$ \\ ${ }^{1}$ Engelhardt Institute of Molecular Biology, Russian Academy of Sciences, Moscow, 119991, Russia \\ ${ }^{2}$ National Medical Research Radiological Center, Ministry of Health of the Russian Federation, Moscow, 125284, Russia \\ ${ }^{3}$ Initium-Pharm, LTD, Moscow, 142000, Russia \\ ${ }^{4}$ Institute of Biology of Komi Science Center of Ural Branch of RAS, Syktyvkar, 167982, Russia \\ ${ }^{5}$ Moscow Institute of Physics and Technology, Dolgoprudny, 141700, Russia \\ *These authors have contributed equally to this work \\ Correspondence to: Alexey Moskalev, email: amoskalev@ib.komisc.ru \\ Keywords: Abies sibirica, plant extract, terpenoids, anti-aging effects, anti-cancer effects \\ Received: August 12, $2016 \quad$ Accepted: October 19, $2016 \quad$ Published: November 19, 2016
}

\section{ABSTRACT}

A large number of terpenoids exhibit potential geroprotector and anti-cancer properties. Here, we studied whole transcriptomic effects of Abisil, the extract of fir (Abies sibirica) terpenes, on normal and cancer cell lines. We used early passaged and senescent none-immortalized fibroblasts as cellular aging models. It was revealed that in normal fibroblasts, terpenes induced genes of stress response, apoptosis regulation and tissue regeneration. The restoration of the expression level of some prolongevity genes after fir extract treatment was shown in old cells. In Caco-2 and ASPC-1 cancer cell lines, Abisil induced expression of both onco-suppressors (members of GADD45, DUSP, and DDIT gene families), and proto-oncogenes (c-Myc, $c-J u n, E G R$ and others). Thus, the study demonstrates the potential anti-aging and anti-cancer effects of Abisil on senescent and cancer cell lines.

\section{INTRODUCTION}

It is known that certain plant extracts have geroprotector properties. The ability to prolong the life in animal models observed for extracts of hawthorn [1], Ginkgo biloba [2], blueberry [3], Rosa damascena [4], ginseng [5], cranberry [6], green tea [7], Nymphaea root [8], Alpinia zerumbet leaf [9], natto [10], Rhodiola rosea [11], black rice [12], garlic [13], apple [14], Stachys lavandulifolia [15], and others. Anti-cancer agents can act as anti-aging drugs [16, 17]. Specific subjects of interest are terpenoids (isoprenoids), the largest class of naturel products that consist of more than 30000 individual compounds [18-20]. They are found in animal, fungi and microbial species, but most of terpenoids are of plant origin [21-23]. Plants produce terpenoids both as primary metabolites and as secondary compounds [24]. Most of terpenoids are derived from a five-carbon precursor isopentenyl diphosphate (IPP) in acetate/ mevalonate (Ac-MVA) pathway [25]. However, some of ones are produced via recently discovered non-mevalonate (non-MVA) pathway [26, 27]. Terpenoids have different functions; in plants they are involved in basic cellular processes such as cell growth and development, cellular membrane maintenance, stress response, and specialized metabolism [28, 29]. A wide range of terpenoids have exhibited anti-cancer and geroprotector activities and are the candidate compounds for drug discovery [30-32]. For example, extracts from Rosa damascene, that is rich in such terpenoid as citronellol, have been shown to increase lifespan of Drosophila by protecting against iron toxicity and enhancing flies resistance to oxidative stress [30, $33,34]$. Betulinic acid, a lupane-type triterpene derived from birch tree (Betula spp.), have demonstrated the antibacterial, antimalarial, and anti-inflammatory properties, activity against the human immunodeficiency virus (HIV), and cytotoxicity towards cancer cells [35-37]. Moreover, both the anti-aging and anti-cancer properties have been observed for such terpenoids as ursolic, maslinic and oleanolic acids [14, 38-41]. Thus, the anti-cancer activity 
and geroprotector properties of terpenoids appear to be promising for various therapeutic applications.

We studied whole transcriptomic effects of Abisil, the extract of Abies sibirica terpenes (10\% bornyl acetate), on human cell lines of colon adenocarcinoma (Caco-2), pancreas adenocarcinoma $(A s P C-1)$ and human noneimmortalized fibroblasts of the $6^{\text {th }}$ and $13^{\text {th }}$ passages from the point of view of potential geroprotector and anticancer properties.

\section{RESULTS AND DISCUSSION}

Differentially expressed genes that were affected by drug treatment in different cell lines were identified (Supplementary Table S1). Abisil changed the expression of genes involved in the adaptive cellular stress response (by 2 and more times, FDR $<0.05$ ) regardless of the number of passages of normal fibroblasts. Among affected genes are heat shock protein 70 (HSPA1B, HSPA1A), heme oxygenase-1, metallothionein $1 \mathrm{X}$, and dual specificity phosphatase 2 (DUSP2).

DUSP2 dephosphorylates MAPKs are involved in cellular proliferation, apoptosis, differentiation, and stress responses [42]. It is known that such geroprotectors and hormetins as curcumin induces expression of an endoplasmic reticulum-anchored enzyme heme oxygenase-1 [43], which is involved in the adaptive response of human fibroblasts to oxidative and chemical stresses $[44,45]$. It utilizes the heme in the various proteins and release ferrous iron [46]. In turn metallothioneins (e.g. MT1X) are induced during cellular stress response involved in detoxification of metal ions [47].

There are also genes associated with the immune response, such as BHLHE40 [48] and IFIT2 [49], and factors related to cell differentiation, such as FOSB [50] and TRIB1 [51]. In addition, TRIB1 plays role in lipid metabolism [52]. The upregulated gene Egr-3 is a transactivator of genes in fibroblasts, associated with tissue remodeling and wound healing [53].

In fibroblasts of both the $6^{\text {th }}$ and $13^{\text {th }}$ passages Abisil suppressed the expression of proapoptotic gene $B M F$ [54] as well as molecules of cell adhesion: integrins ITGB7, ITGAM [55] and cell surface glycoprotein MUC13 [56].

It should be noted, that among the most represented molecular pathways induced by Abisil treatment in normal fibroblasts, a significant portion is related to longevity, including MAPK-, FOXO- and HIF-1 signaling pathways (Figure 1) [57].

It is noteworthy that in normal fibroblasts of the $13^{\text {th }}$ passage Abisil alters the expression level of a much larger number of genes than in the cells of the $6^{\text {th }}$ passage. When the selected threshold of expression was 2-fold or more $($ FDR $<0.05)$ in the cells of the $6^{\text {th }}$ passage, Abisil activated 21 genes and repressed 16 genes, whereas in cells of the $13^{\text {th }}$ passage, the expression level of 43 and 67 genes were affected, respectively. This result may reflect the greater randomness of the expression response in old cells compared to younger ones. Some authors have mentioned the age-dependent increase of cell-to-cell variation in gene expression, so called increased transcriptional noise [58,59]. Among the 31 upregulated genes which alter their activity only in fibroblasts of the $13^{\text {th }}$ passage, the most represented genes are of apoptosis (12 genes) and MAPK signaling pathway (5 genes). Among the 62 downregulated genes in fibroblasts of the $13^{\text {th }}$ passage, the BTG2 gene is the one most associated with cellular aging in our opinion. Its expression has been shown to be important in negatively regulating cell proliferation [60]. Thus, terpenes of fir extract induce in normal fibroblasts genes of stress response, apoptosis regulation, and tissue regeneration.

In this study, fibroblast passaging was considered as one of the models of aging. Fibroblasts of the $13^{\text {th }}$ passage exhibit various external signs of cellular aging, such as inhibition of proliferation as compared with the $6^{\text {th }}$ passage (control). When comparing the expression of old and young fibroblasts 5804 differentially expressed genes were revealed generally.

The following aging-associated features of the expression profiles in fibroblasts should be noted: reduced expression of various cell adhesion molecules, chemokines expression, cyclin-dependent kinases, lamin, GADD45 family members, cAMP-dependent transcription factors (CREB), and PI3K/Akt overexpression. GSEA analysis allowed us to identify a number of biological processes, with the strongest changes in gene expression being (as part of this aging model): the suppression of angiogenesis, cell differentiation, MAPK cascade, chemotaxis, response to hypoxia, tissue regeneration and other processes, as well as modulation of intercellular communication, adhesion, migration, and ion exchange.

The potential geroprotector may be able to restore the expression level of genes in old cells, and transform them into younger cell gene expression profiles [61]. The possible mechanisms of the potential geroprotective effect of Abisil are:

- GADD45 (growth arrest and DNA damage inducible protein) gene family is associated with both tumor suppression and with the longevity. The expression level of GADD45 was reduced by 2 -fold in fibroblasts of the $13^{\text {th }}$ passage compared with the $6^{\text {th }}$ passage. At the same time, Abisil treatment caused a 2-fold increase of expression level of GADD45B/G genes and 1.5-fold increase - of GADD45A.

- Abisil treatment is accompanied by a 1.5 to3-fold increase in the expression of heat shock proteins genes HSPA1B, HSPA1A, DNAJB9 (Hsp40 B9), DNAJB4 (Hsp40 B4), HSPH1, DNAJB1 (Hsp40 B1), HSPA9, and others.

- Modulation of the cell cycle, in particular the MAPK signaling pathway.

- Modulation of NF- $\kappa$ B signaling pathway.

- Modulation of Toll-like receptor signaling pathway. 
- Modulation of TGF-beta signaling pathway.

Also worthy of attention is the induction of compensatory changes for the following genes:

- Expression of tumor-suppressive regulators of MAPKsignaling cascade DUSP5, DUSP1, and DUSP6 (dual specificity phosphatases) decreases with fibroblasts aging (in the $13^{\text {th }}$ passage compared with the $6^{\text {th }}$ ). Abisil treatment restores it to a level above the previous level.

- The expression level of MYC (v-myc avian myelocytomatosis viral oncogene homolog), JUN (jun proto-oncogene), FOSB (FBJ murine osteosarcoma viral oncogene homolog B), FOSL1 (FOS-like antigen 1) protooncogenes decreases during fibroblasts aging. Abisil treatment restores it to a level of younger cells.

- The expression level of SOCS3 (suppressor of cytokine signaling 3) decreases with aging. Abisil treatment restores it to a level of early passages.

- CREB5 (cAMP responsive element binding protein 5) gene expression is decreased during aging and restored to the previous level after Abisil supplementation.
- DDIT3 (DNA damage inducible transcript 3) gene expression is decreased during aging and restored to the previous level after Abisil supplementation.

- KLF2 and KLF4 (Kruppel-like factors 2 and 4) expression is decreased during aging and restored to the previous level after Abisil supplementation.

- $B M F$ (Bcl2 modifying factor), TRIB3 (tribbles pseudokinase 3), BHLHE40 (basic helix-loop-helix family member e40), TLR4 (toll-like receptor 4), RGS4 (regulator of G-protein signaling 4), GDF15 (growth differentiation factor 15), NGFR (nerve growth factor receptor), and $C T G F$ (connective tissue growth factor) gene expression is increased during aging and restored to the previous level after Abisil supplementation.

Among global mortality rates for cancer, pancreas cancer takes $6^{\text {th }}$ place, and colon cancer takes $3^{\text {th }}$ place $[62,63]$. We have studied Abisil's effects on the gene expression level in human cell lines of colon adenocarcinoma ( $\mathrm{CacO}-2)$ and pancreas adenocarcinoma (AsPC-1).

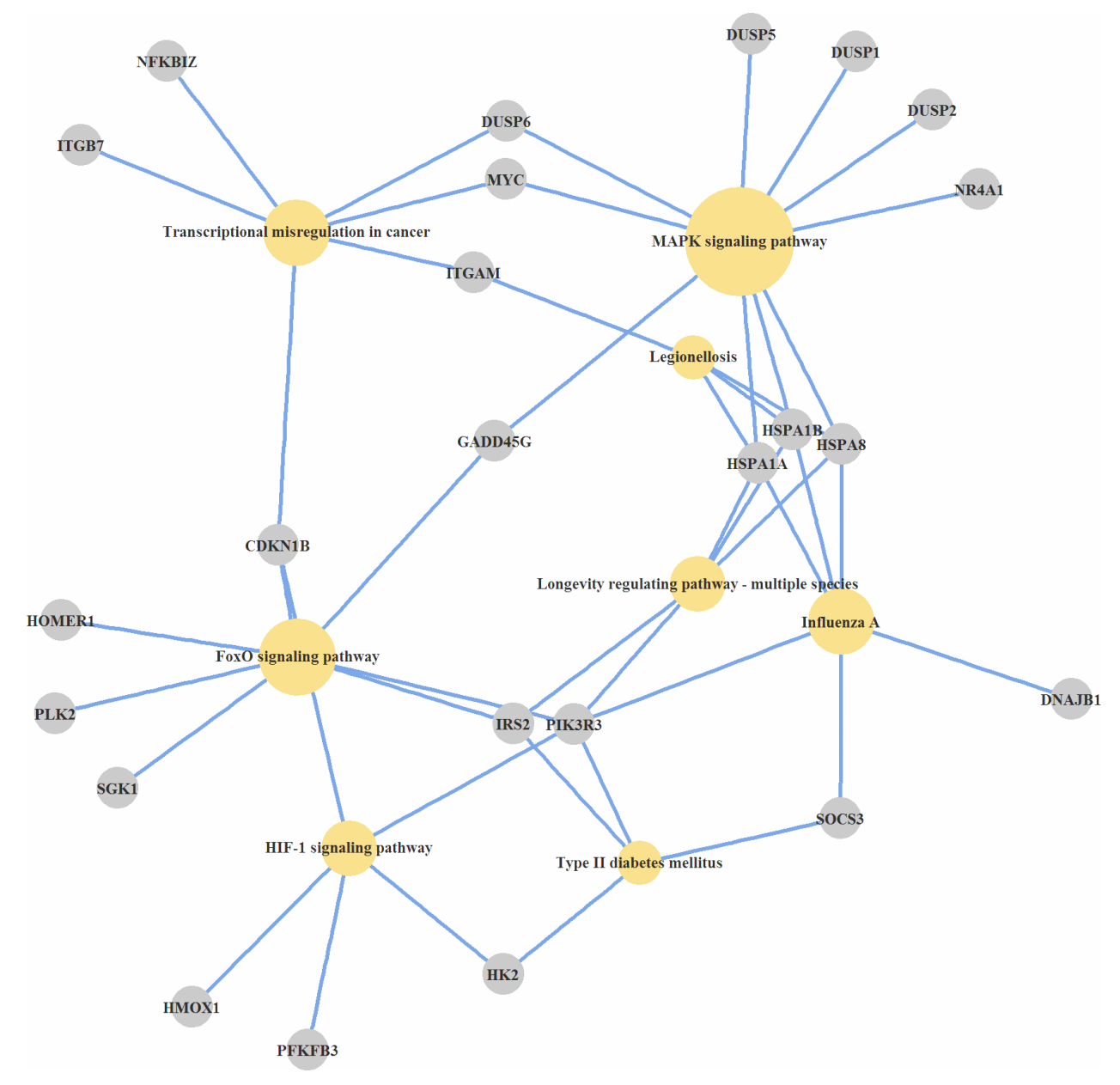

Figure 1: KEGG pathways, over-represented by genes, induced by Abisil in normal fibroblasts. Differentially expressed genes, cell pathways and processes at the organism level, wich are statistically significant over-represented in the GSEA-analysis, are presented. 
Table 1: The results of GSEA (GO) for the top 300 of overexpressed genes (Caco-2 and $A s P C$ - 1 cell lines, averaged)

GeneOntology process

Apoptotic process

Intercellular signal transduction

Cellular response to organic substance

\section{Genes}

EGR3, INHBA, PDK4, JUN, CTGF, DDIT4, GDF15, EGR2, EPHA2, EGR4, CLCF1, MYC, GCLM, CXCR3, PPP1R15A, VEGFA, RFFL, OSGIN1, EGR1, GADD45B, CYR61, SNAI2, SOCS3, THBS1, FOSL1, SERPINE1, ID1, CEBPB, DDIT3, DUSP6, DSG3, EDAR, BMP2, PLK2, PLK3, ATF3, C8orf4, SPRY2, ANXA1, TNFRSF1A, PMAIP1, TNFSF15, ASNS, SOX9, NUAK2, RNF41, PIM1, CTH, SIAH2, TNFRSF10B, GATA6, SQSTM1, IER3, CHAC1, STK40, TCF7L2, GADD45A, SOCS2, RIPK2, BIRC3, RHOB, FOXO3, F3, TNFSF9, PAWR, WNT7B, ARHGEF2, ADM, H1F0, ZC3H12A, HERPUD1, HK2, NCF2, DUSP1, ANKRD1, AEN, BBC3, PLEKHG2, EDN1, CITED2, GADD45G

INHBA, CXCL8, ARL14, JUN, CTGF, DDIT4, GDF15, EPHA2, CLCF1, MYC, CXCR3, PPP1R15A, VEGFA, RFFL, RND3, GADD45B, CCL20, DUSP4, CYR61, SNAI2, SOCS3, THBS1, EDN2, ID1, CEBPB, NFATC1, DDIT3, NFKB2, DUSP6, EREG, EDAR, BMP2, ARHGAP32, PLK2, FAM110C, PLK3, DGKD, ATF3, C8orf4, SPRY2, TNFRSF1A, TRIB1, PMAIP1, PLCH1, DUSP8, TNFSF15, SOX9, NUAK2, RNF41, CTH, SIAH2, TNFRSF10B, GAB2, SQSTM1, SESN2, IER3, LIF, CHAC1, CYTH1, SPSB1, DVL1, STK40, TCF7L2, GADD45A, SOCS2, RIPK2, BIRC3, CCDC88C, NFATC2, HRH1, SPRY4, RHOB, FOXO3, F3, CSF1, WNT7B, ARHGEF2, ARFRP1, ADM, FOS, HERPUD1, NCF2, DUSP1, ANKRD1, AEN, BBC3, DGKE, RAPGEF5, HBEGF, RAP1GAP2, PLEKHG2, WWC1, EDN1, GPAT3, AVPI1, GADD45G

EGR3, INHBA, CXCL8, PDK4, JUN, CTGF, DDIT4, GDF15, EGR2, EGR4, CLCF1, MYC, CXCR3, PPP1R15A, VEGFA, RFFL, EGR1, CXCL3, CCL20, DUSP4, CYR61, SNAI2, SOCS3, THBS1, TGIF1, SERPINE1, EDN2, ID1, KLF6, CEBPB, DDIT3, NFKB2, DUSP6, KLF2, EREG, EDAR, BMP2, MT1G, ATF3, CPEB2, SPRY2, ANXA1, TNFRSF1A, TRIB1, TNFSF15, ASNS, SOX9, PIM1, CTH, GATA6, SQSTM1, SYBU, MT1X, OASL, SOCS2, RIPK2, NEDD4L, BIRC3, HRH1, DKK1, CALB1, FAM83G, FOXO3, MT2A, F3, CSF1, NR1D1, PAWR, WNT7B, ARHGEF2, FOS, ZC3H12A, HERPUD1, NCF2, DUSP1, HDAC5, ANKRD1, BBC3, JUND, HBEGF, PLEKHG2, EDN1, CITED2
It is noteworthy the increased expression level of all three genes (GADD45A, GADD45B, and GADD45G) related to the GADD45 family - both in normal fibroblasts and tumor cell lines (AsPC-1 and Caco-2). GADD45 family proteins are stress sensors and involved in the intersection of several cell signaling pathways, including apoptosis, DNA repair, and cell cycle arrest [64]. Defects in the GADD45 genes often accompany the initiation and progression of malignancies, and GADD45 mediates the effects of multiple chemotherapeutic drugs [65]. For example, it has been shown that the sensitivity of prostate adenocarcinoma cell lines to docetaxel increased by enhancing the expression of $G A D D 45 A$, but lack of $G A D D 45$ expression, however, can cause inefficiencies of chemotherapy [66]. Simultaneously GADD45 activity can have anti-aging effects as well $[67,68]$.

The overexpression of DUSP1-2, DUSP4-6, and DUSP 8 genes also should be noted. Many genes of the DUSP family are responsible for the suppression of MAPK signal transduction cascade, thereby being the tumor suppressor genes, that are responsible for the effectiveness of chemotherapy [69-74].

In both $\mathrm{Caco}-2$ and $A s P C$ - 1 cancer cell lines Gene Ontology processes were enriched by overexpressed genes of apoptosis, intercellular signal transduction, and cellular response to organic substance (Table 1).

Thus, the analysis of over-represented pathways across differentially expressed genes revealed the number of cellular mechanisms that are modulated by Abisil (Figures 1-3). Among them: "MAPK signaling pathway", "p53 signaling pathway", "Apoptosis", "Cell cycle", "Transcriptional misregulation in cancer", "HIF1 signaling pathway", "FOXO signaling pathway", "TGF signaling pathway", "TNF signaling pathway", "Amino sugar and nucleotide sugar metabolism", and "Protein processing in endoplasmic reticulum". There are also a series of processes at the organismal level: "Longevity regulating pathway", "Type II diabetes mellitus", "Insulin resistance", and "Infectious diseases (Influenza A, Legionellosis)". The last one suggests the potential effect (it is difficult discuss about the direction of this effect a 


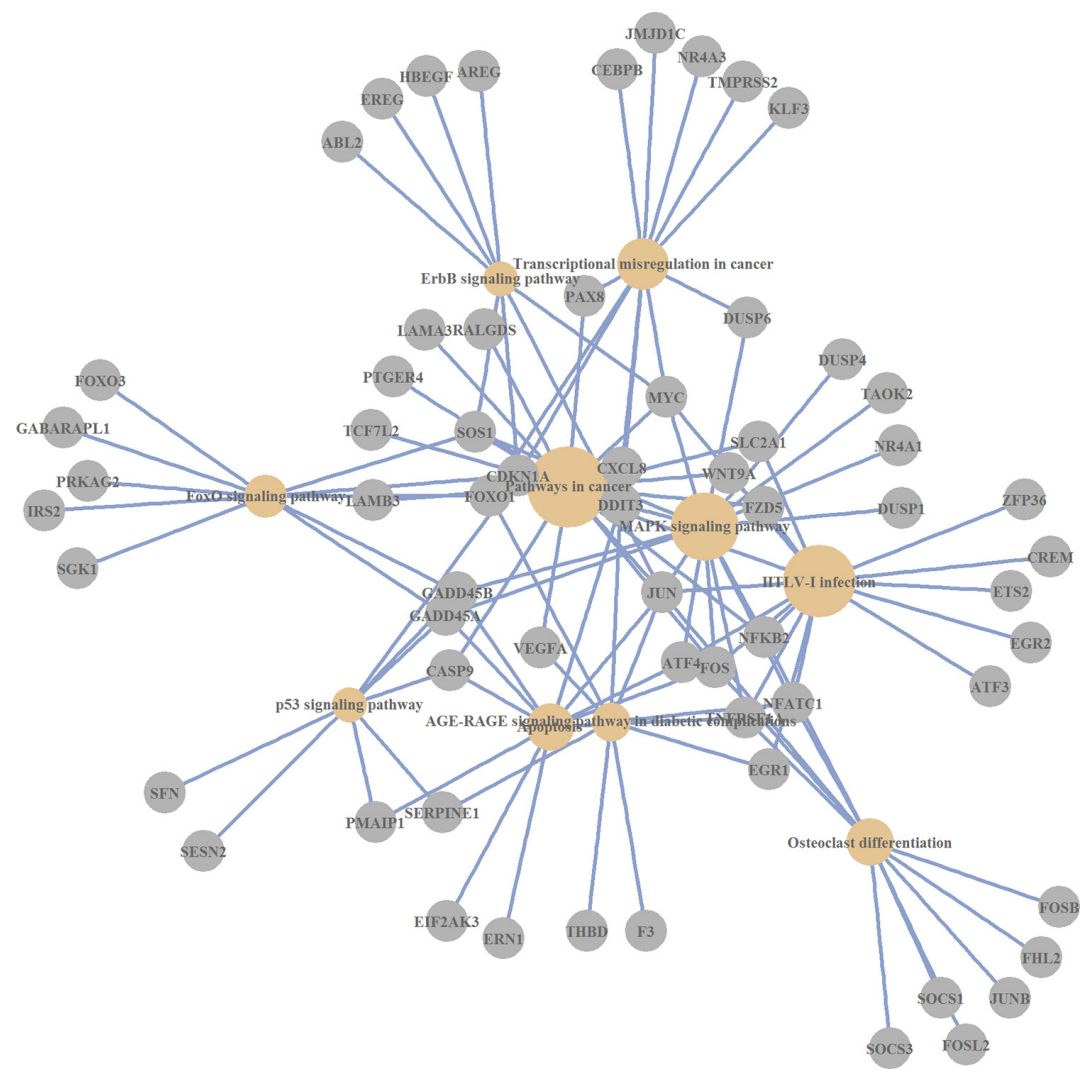

Figure 2: KEGG pathways, which are over-represented by differentially expressed genes (AsPC-1 cell line).

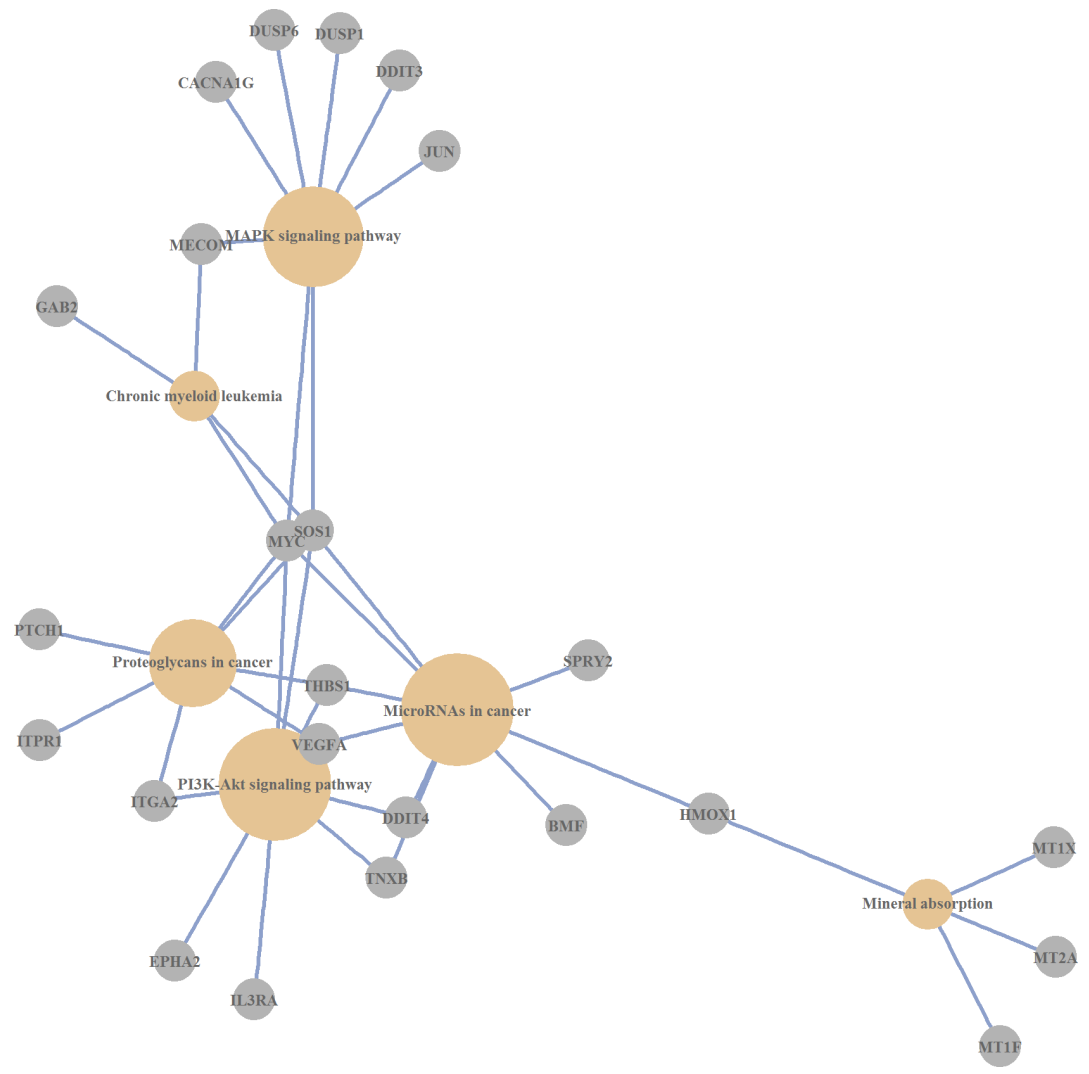

Figure 3: KEGG pathways, which are over-represented by differentially expressed genes (Caco-2 cell line). 
priori) ofAbisil on the penetration and proliferation of infectious agents or immune response.

As a result of the drug supplementation in all examined cell lines the expression level of several thousand genes changed. In general, the effects of increase in the expression level prevailed.

The top list includes both overexpressed oncosuppressors (gene of the GADD45, DUSP, and DDIT families), and proto-oncogenes (genes of c-Myc, c-Jun, EGR families and others.). Data indicate that Abisil exposure was associated with the modulation of key signaling pathways responsible for cell cycle control, proliferation, differentiation, apoptosis (e.g., MAPK, TNF, p53, FOXO, and TGF signaling pathways), cell-cell signaling, stress response, cAMP-dependent signaling and protein refolding.

Of particular note is the increase in the expression of all three members of the GADD 45 family genes which may serve as tumor suppressors. Chemotherapeutic drugs induced up-regulation of these genes is one of the factors, that determines the effectiveness of chemotherapy. Another important effect is the overexpression of most of the DUSP family genes responsible for the inhibition of the MAPK cascade, which plays a role in the response to chemotherapy as well.

The results of GSEA-Gene Ontology analysis allows one to make the assumption that the biological processes responsible for the negative regulation of apoptosis, prevail over the processes of induction of programmed cell death in normal human fibroblasts. In the cell lines $\mathrm{Caco}-2$ and $A s P C-1$ the situation is reversed.

The potential geroprotector properties of Abisil may be conditioned by induced overexpression of both $G A D D 45$ gene family, and the family of heat shock proteins $H S P A 1 A / A 1 B / A 9, H s p 40 B 1 / B 4 / B 9$, and $H S P H 1$.

\section{MATERIALS AND METHODS}

\section{Abisil composition}

Pharmaceutical composition Abisil ${ }^{\circledR}$ is a complex of terpenoids obtained from capsule extract Abies sibirica of Penaceae family enriched with monoterpenoids. Chemical and quantitative composition of the pharmaceutical composition of Abisil was studied with gas-liquid chromatography (GLC) by LCM-7A chromatograph (Chromatograph, Russia) using a thermal conductivity detector (TCD), packed column (length of $3.0 \mathrm{~m}$, a diameter of $5 \mathrm{~mm}$ ), and stationary phase "Apiezon L" (M\&I Materials Limited, United Kingdom) on polychrome. The consumption of carrier gas (helium) was $30 \mathrm{ml} / \mathrm{min}$, with a column temperature of $125^{\circ} \mathrm{C}$, and a vaporization chamber temperature of $180^{\circ} \mathrm{C}$. Identification of the main components was carried on the relative retention times and "bystander" compounds. The revealed
Abisil composition is a standardized terpenoid substance derived from capsule extract of Abies sibirica (Table 2).

The terpenoid composition is a thick liquid from yellow transparent to milky white in color and has a specific odor. It has certain physical constants, namely: an acid number (70-90 mg), a saponification number (100$130 \mathrm{mg}$ ), an ester number $(10-60 \mathrm{mg})$, and an index of refraction $(1,500$ to 1,520$)$.

\section{Cell culturing}

Human pancreas adenocarcinoma cell line AsPC1 (ATCC - CRL-1682) and colorectal adenocarcinoma cell line Caco-2 (ATCC - HTB-37) were kindly provided by Dr. Peter Chumakov (EIMB RAS, Moscow, Russia). Cells were maintained in Dulbecco's modified Eagle's medium (DMEM, Invitrogen, USA) supplemented with $10 \%$ and $20 \%$ fetal bovine serum (Harlan Sera-Lab, Loughborough, UK) accordingly, $100 \mathrm{U}$ penicillin per $\mathrm{ml}$ and $100 \mathrm{mkg}$ streptomycin per $\mathrm{ml}$ (Gibco, Thermo Fisher Scientific, USA). Cells were cultured at $37^{\circ} \mathrm{C}$ in a $5 \% \mathrm{CO}_{2}$ atmosphere and passaged every 2-3 days by dissociation with trypsin (Gibco, Thermo Fisher Scientific, USA).

Primary fibroblasts were provided by The Laboratory of Cell Cultures of the Institute of Medical Cell Technologies (Ekaterinburg, Russia). Cells were maintained in the medium described above (with $10 \%$ FBS). Cells were passaged, when the culture had reached approximately $80 \%$ confluence. In order to save unique properties of the model, cells were frozen in DMEM with $7 \%$ DMSO and $30 \%$ FBS after the $4^{\text {th }}$ and $10^{\text {th }}$ passages. Effects were studied on the $6^{\text {th }}$ and $13^{\text {th }}$ passages.

Cells in $70 \%$ confluence were treated for 6 hours with dilution of Abisil $(1.2 \mathrm{mg} / \mathrm{ml})$ in DMEM with $2 \%$ FBS. After that, the culture medium was replaced with a fresh medium and in 18 hours cell viability was analyzed using MTS test (Promega, USA).

All cells including control cell lines were plated in triplicate. RNA extraction for further analysis was performed right after treatment with active substance dilution.

\section{RNA extraction and quality control}

Total RNA was extracted from 24 samples using RNeasy Mini kit (Qiagen, Germany), including 4 cell lines after treatment (Caco-2, AsPC-1, and primary fibroblasts at the $6^{\text {th }}$ and $13^{\text {th }}$ passages) and corresponding control cells (all in triplicates). RNA quality and quantity was determined with the Agilent 2100 Bioanalyzer (Agilent Technologies, USA) and the Qubit 2.0 Fluorimeter (Thermo Fisher Scientific, Invitrogen, USA), respectively. RNA samples with an RNA integrity number (RIN) higher than 8.0 were used for downstream analysis. 
Table 2: The composition of Abisil

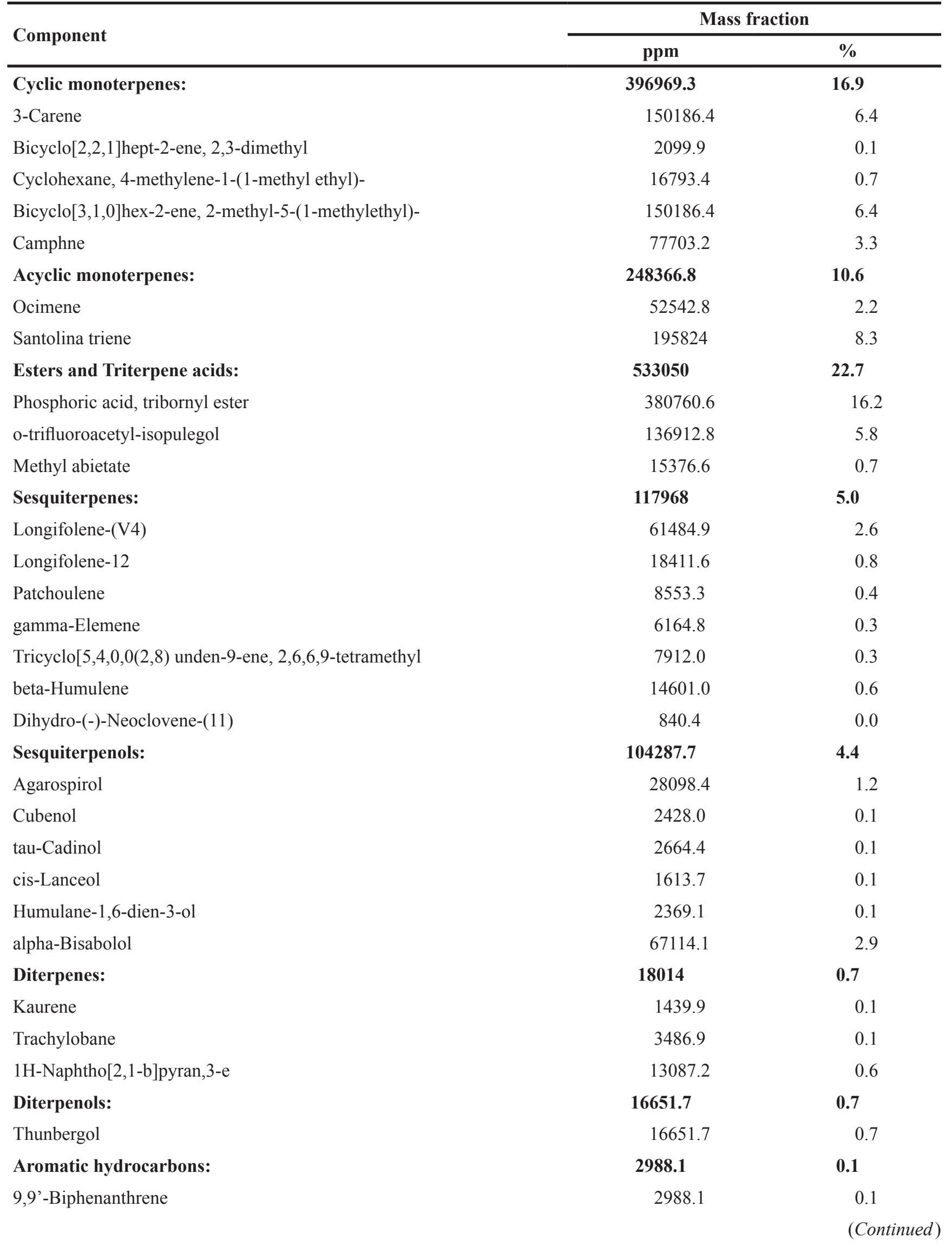




\begin{tabular}{lcc}
\hline \multirow{2}{*}{ Component } & Mpm & $\mathbf{\%}$ \\
\cline { 2 - 3 } Steroids and Hormones: & $\mathbf{4 6 1 7 9 . 6}$ & $\mathbf{2 . 0}$ \\
9,9'-Biphenanthrene & 1228.1 & 0.1 \\
Resibufogenin & 29023.1 & 1.2 \\
9(11)-Dehydrotestosterone & 15928.4 & 0.7 \\
Spirits: & $\mathbf{1 1 4 9 . 1}$ & $\mathbf{0 . 0 0 5}$ \\
1-Heptatriacotanol & 1149.1 & 0.005 \\
Cycloalkanes: & $\mathbf{5 4 1 6 1 0 . 7}$ & $\mathbf{2 3 . 0}$ \\
1,3,5,6-Tetramethyladamantane & 541610.7 & 23.0 \\
Diterpene acids: & $\mathbf{3 2 3 6 0 9 . 2}$ & $\mathbf{1 5 . 4}$ \\
Palustric acid & 57733.0 & 2.5 \\
Abietic acid & 247651.0 & 10,5 \\
beta-Pimaric acid & 18225.2 & 2.5 \\
\hline
\end{tabular}

\section{RNA library preparation and sequencing}

Total RNA $(2 \mu \mathrm{g})$ from each sample was used for mRNA library preparation with a TruSeq RNA Sample Preparation Kit v2 Low Sample (LS) protocol (Illumina, USA) according to the manufacturer's instructions. The quality and concentration of cDNA library was assessed using an Agilent 2100 Bioanalyzer (Agilent Technologies) and a Qubit 2.0 fluorometer (Invitrogen), respectively, before sequencing. To optimizing cluster densities, the libraries were quantified by qPCR. cDNA libraries were sequenced (single end reads, $75 \mathrm{bp}$ ) on an Illumina NextSeq 500 platform (EIMB RAS "Genome" center, Russia).

\section{Processing of RNA-Seq data and differential expression analysis}

The raw single end reads were quality controlled and trimmed using FastQC (http://www.bioinformatics. babraham.ac.uk/projects/fastqc/) and Trimmomatic (http:// www.usadellab.org/cms/index.php?page=trimmomatic) tools with default parameters. The clean reads were separately aligned to the human reference genome (GRCh38) in the Ensembl (release 80) using TopHat2 software (http://ccb.jhu.edu/software/tophat/index.shtml). The read counting was performed with HTSeq-count (http://www-huber.embl.de/HTSeq/doc/overview.html).

The differentially expressed genes were determined with the $p$-value $\leq 0.01$ using the edgeR, lme4, biomaRt, Rgraphviz, topGO, ggplot2, pathview, and clusterProfiler analysis packages in $\mathrm{R}$.

\section{ACKNOWLEDGMENTS}

Authors thank Laboratory of Cell Cultures of the Institute of Medical Cell Technologies (Ekaterinburg, Russia) and Dr. Peter Chumakov (EIMB RAS, Moscow, Russia) for cell cultures. Authors thank Initium-Pharm, LTD for supplying Abisil, and data analysis; National Medical Research Center of Radiology and Institute of Biology of Komi Science Center of Ural Branch of RAS for experimental setup, scientific advice and useful suggestions. Part of this work (RNA extraction and quantification, quality control, mRNA library preparation, and NGS) was performed at the EIMB RAS "Genome" center (Moscow, Russia) (http://www.eimb.ru/RUSSIAN_ NEW/INSTITUTE/ccu_genome_c.php).

\section{CONFLICTS OF INTEREST}

No conflict of interest from all participating authors.

\section{FUNDING}

The work was supported by the Russian Science Foundation Grant no.14-50-00060.

\section{Author contributions}

A.K. and A.M. conceived and supervised the project. A.M., A.K., and G.K. designed the study and analyzed the data. A.L., A.S., and M.F. carried out the experiments. F.M. provided the Abisil and analyzed its composition. A.K., G.K., and A.M. wrote the manuscript. M.S. assisted in the preparation and writing of the manuscript. 


\section{REFERENCES}

1. Zhang Y, Shen T-T, Liu S-W, Zhao J, Chen W, Wang H. Effect of Hawthorn on Drosophila Melanogaster Antioxidant-Related Gene Expression. Tropical Journal of Pharmaceutical Research. 2014; 13: 353-7. doi: 10.4314/ tjpr.v13i3.6.

2. Wu Z, Smith JV, Paramasivam V, Butko P, Khan I, Cypser JR, Luo Y. Ginkgo biloba extract EGb 761 increases stress resistance and extends life span of Caenorhabditis elegans. Cell Mol Biol (Noisy-le-grand). 2002; 48: 725-31. doi:

3. Peng C, Zuo Y, Kwan KM, Liang Y, Ma KY, Chan HY, Huang Y, Yu H, Chen ZY. Blueberry extract prolongs lifespan of Drosophila melanogaster. Exp Gerontol. 2012; 47: 170-8. doi: 10.1016/j.exger.2011.12.001.

4. Jafari M, Zarban A, Pham S, Wang T. Rosa damascena decreased mortality in adult Drosophila. J Med Food. 2008; 11: 9-13. doi: 10.1089/jmf.2007.546.

5. Kim MS. Korean Red Ginseng Tonic Extends Lifespan in D. melanogaster. Biomol Ther (Seoul). 2013; 21: 241-5. doi: 10.4062/biomolther.2013.024.

6. Wang L, Li YM, Lei L, Liu Y, Wang X, Ma KY, Chen ZY. Cranberry anthocyanin extract prolongs lifespan of fruit flies. Exp Gerontol. 2015; 69: 189-95. doi: 10.1016/j. exger.2015.06.021.

7. Lopez T, Schriner SE, Okoro M, Lu D, Chiang BT, Huey J, Jafari M. Green tea polyphenols extend the lifespan of male drosophila melanogaster while impairing reproductive fitness. J Med Food. 2014; 17: 1314-21. doi: 10.1089/ jmf.2013.0190.

8. Zhuang Z, Lv T, Li M, Zhang Y, Xue T, Yang L, Liu H, Zhang W. The lifespan-extending effects of Nymphaea hybrid root extract in the nematode Caenorhabditis elegans. Plant Foods Hum Nutr. 2014; 69: 304-9. doi: 10.1007/ s11130-014-0448-3.

9. Upadhyay A, Chompoo J, Taira N, Fukuta M, Tawata S. Significant longevity-extending effects of Alpinia zerumbet leaf extract on the life span of Caenorhabditis elegans. Biosci Biotechnol Biochem. 2013; 77: 217-23. doi: 10.1271/bbb. 120351.

10. Ibe S, Kumada K, Yoshida K, Otobe K. Natto (fermented soybean) extract extends the adult lifespan of Caenorhabditis elegans. Biosci Biotechnol Biochem. 2013; 77: 392-4. doi: 10.1271/bbb.120726.

11. Schriner SE, Abrahamyan A, Avanessian A, Bussel I, Maler S, Gazarian M, Holmbeck MA, Jafari M. Decreased mitochondrial superoxide levels and enhanced protection against paraquat in Drosophila melanogaster supplemented with Rhodiola rosea. Free Radic Res. 2009; 43: 836-43. doi: 10.1080/10715760903089724.

12. Zuo Y, Peng C, Liang Y, Ma KY, Yu H, Edwin Chan HY, Chen ZY. Black rice extract extends the lifespan of fruit flies. Food Funct. 2012; 3: 1271-9. doi: 10.1039/ c2fo30135k
13. Huang CH, Hsu FY, Wu YH, Zhong L, Tseng MY, Kuo CJ, Hsu AL, Liang SS, Chiou SH. Analysis of lifespanpromoting effect of garlic extract by an integrated metaboloproteomics approach. J Nutr Biochem. 2015; 26: 808-17. doi: 10.1016/j.jnutbio.2015.02.010.

14. Vayndorf EM, Lee SS, Liu RH. Whole apple extracts increase lifespan, healthspan and resistance to stress in Caenorhabditis elegans. J Funct Foods. 2013; 5: 1236-43. doi: 10.1016/j.jff.2013.04.006.

15. Altun D, Ayar A, Uysal H, Kara AA, Unal EL. Extended longevity of Drosophila melanogaster by water and ethanol extracts of Stachys lavandulifolia. Pharm Biol. 2010; 48: 1291-6. doi: 10.3109/13880201003789424.

16. Danilov A, Shaposhnikov M, Plyusnina E, Kogan V, Fedichev P, Moskalev A. Selective anticancer agents suppress aging in Drosophila. Oncotarget. 2013; 4: 150726. doi: 10.18632/oncotarget. 1272 .

17. Blagosklonny MV. Selective anti-cancer agents as antiaging drugs. Cancer Biol Ther. 2013; 14: 1092-7. doi: 10.4161/cbt.27350.

18. Sacchettini JC, Poulter CD. Creating isoprenoid diversity. Science. 1997; 277: 1788-9. doi: 10.1126/ science.277.5333.1788.

19. Dewick PM. The biosynthesis of C5-C25 terpenoid compounds. Nat Prod Rep. 2002; 19: 181-222. doi: 10.1039/B002685I.

20. Thoppil RJ, Bishayee A. Terpenoids as potential chemopreventive and therapeutic agents in liver cancer. World J Hepatol. 2011; 3: 228-49. doi: 10.4254/wjh. v3.i9.228.

21. Yamada Y, Kuzuyama T, Komatsu M, Shin-Ya K, Omura S, Cane DE, Ikeda H. Terpene synthases are widely distributed in bacteria. Proc Natl Acad Sci U S A. 2015; 112: 857-62. doi: 10.1073/pnas.1422108112.

22. Ishida T. Biotransformation of terpenoids by mammals, microorganisms, and plant-cultured cells. Chem Biodivers. 2005; 2: 569-90. doi: 10.1002/cbdv.200590038.

23. Schmidt-Dannert C. Biosynthesis of terpenoid natural products in fungi. Adv Biochem Eng Biotechnol. 2015; 148: 19-61. doi: 10.1007/10_2014_283.

24. Hussain MS, Fareed S, Ansari S, Rahman MA, Ahmad IZ, Saeed M. Current approaches toward production of secondary plant metabolites. J Pharm Bioallied Sci. 2012; 4: 10-20. doi: 10.4103/0975-7406.92725.

25. McGarvey DJ, Croteau R. Terpenoid metabolism. Plant Cell. 1995; 7: 1015-26. doi: 10.1105/tpc.7.7.1015.

26. Rohmer M. The discovery of a mevalonate-independent pathway for isoprenoid biosynthesis in bacteria, algae and higher plants. Nat Prod Rep. 1999; 16: 565-74. doi: 10.1039/A709175C.

27. Dubey VS, Bhalla R, Luthra R. An overview of the nonmevalonate pathway for terpenoid biosynthesis in plants. $\mathrm{J}$ Biosci. 2003; 28: 637-46. doi: 
28. Roberts SC. Production and engineering of terpenoids in plant cell culture. Nat Chem Biol. 2007; 3: 387-95. doi: 10.1038/nchembio.2007.8.

29. Tholl D. Biosynthesis and biological functions of terpenoids in plants. Adv Biochem Eng Biotechnol. 2015; 148: 63-106. doi: 10.1007/10_2014_295.

30. Dong Y, Guha S, Sun X, Cao M, Wang X, Zou S. Nutraceutical interventions for promoting healthy aging in invertebrate models. Oxid Med Cell Longev. 2012; 2012: 718491. doi: 10.1155/2012/718491.

31. Cragg GM, Newman DJ. Plants as a source of anti-cancer agents. J Ethnopharmacol. 2005; 100: 72-9. doi: 10.1016/j. jep.2005.05.011.

32. Srivastava V, Negi AS, Kumar JK, Gupta MM, Khanuja SP. Plant-based anticancer molecules: a chemical and biological profile of some important leads. Bioorg Med Chem. 2005; 13: 5892-908. doi: 10.1016/j.bmc.2005.05.066.

33. Kumar N, Bhandari P, Singh B, Gupta AP, Kaul VK. Reversed phase-HPLC for rapid determination of polyphenols in flowers of rose species. J Sep Sci. 2008; 31: 262-7. doi: 10.1002/jssc.200700372.

34. Schriner SE, Katoozi NS, Pham KQ, Gazarian M, Zarban A, Jafari M. Extension of Drosophila lifespan by Rosa damascena associated with an increased sensitivity to heat. Biogerontology. 2012; 13: 105-17. doi: 10.1007/ s10522-011-9357-0.

35. Cichewicz RH, Kouzi SA. Chemistry, biological activity, and chemotherapeutic potential of betulinic acid for the prevention and treatment of cancer and HIV infection. Med Res Rev. 2004; 24: 90-114. doi: 10.1002/med.10053.

36. Fulda S. Betulinic Acid for cancer treatment and prevention. Int J Mol Sci. 2008; 9: 1096-107. doi: 10.3390/ ijms9061096.

37. Yogeeswari P, Sriram D. Betulinic acid and its derivatives: a review on their biological properties. Curr Med Chem. 2005; 12: 657-66. doi:

38. Lin CC, Huang CY, Mong MC, Chan CY, Yin MC. Antiangiogenic potential of three triterpenic acids in human liver cancer cells. J Agric Food Chem. 2011; 59: 755-62. doi: 10.1021/jf103904b.

39. Lozano-Mena G, Sanchez-Gonzalez M, Juan ME, Planas JM. Maslinic acid, a natural phytoalexin-type triterpene from olives-a promising nutraceutical? Molecules. 2014; 19: 11538-59. doi: 10.3390/molecules190811538.

40. Xiang L, Chi T, Tang Q, Yang X, Ou M, Chen X, Yu X, Chen J, Ho RJ, Shao J, Jia L. A pentacyclic triterpene natural product, ursolic acid and its prodrug US597 inhibit targets within cell adhesion pathway and prevent cancer metastasis. Oncotarget. 2015; 6: 9295-312. doi: 10.18632/ oncotarget.3261.

41. Zhang J, Lu L, Zhou L. Oleanolic acid activates daf-16 to increase lifespan in Caenorhabditis elegans. Biochem Biophys Res Commun. 2015; 468: 843-9. doi: 10.1016/j. bbrc.2015.11.042.
42. Patterson KI, Brummer T, O'Brien PM, Daly RJ. Dualspecificity phosphatases: critical regulators with diverse cellular targets. Biochem J. 2009; 418: 475-89. doi: 10.1042/BJ20082234.

43. Lima CF, Pereira-Wilson C, Rattan SI. Curcumin induces heme oxygenase-1 in normal human skin fibroblasts through redox signaling: relevance for anti-aging intervention. Mol Nutr Food Res. 2011; 55: 430-42. doi: 10.1002/mnfr.201000221.

44. Bansal S, Biswas G, Avadhani NG. Mitochondriatargeted heme oxygenase-1 induces oxidative stress and mitochondrial dysfunction in macrophages, kidney fibroblasts and in chronic alcohol hepatotoxicity. Redox Biol. 2014; 2: 273-83. doi: 10.1016/j.redox.2013.07.004.

45. Vile GF, Basu-Modak S, Waltner C, Tyrrell RM. Heme oxygenase 1 mediates an adaptive response to oxidative stress in human skin fibroblasts. Proc Natl Acad Sci U S A. 1994; 91: 2607-10. doi:

46. Ryter SW, Alam J, Choi AM. Heme oxygenase-1/ carbon monoxide: from basic science to therapeutic applications. Physiol Rev. 2006; 86: 583-650. doi: 10.1152/ physrev.00011.2005.

47. Schulkens IA, Castricum KC, Weijers EM, Koolwijk P, Griffioen AW, Thijssen VL. Expression, regulation and function of human metallothioneins in endothelial cells. J Vasc Res. 2014; 51: 231-8. doi: 10.1159/000365550.

48. Kanda M, Yamanaka H, Kojo S, Usui Y, Honda H, Sotomaru Y, Harada M, Taniguchi M, Suzuki N, Atsumi T, Wada H, Baghdadi M, Seino K. Transcriptional regulator Bhlhe40 works as a cofactor of T-bet in the regulation of IFN-gamma production in iNKT cells. Proc Natl Acad Sci U S A. 2016; 113: E3394-402. doi: 10.1073/pnas.1604178113.

49. Fensterl V, Wetzel JL, Sen GC. Interferon-induced protein Ifit 2 protects mice from infection of the peripheral nervous system by vesicular stomatitis virus. J Virol. 2014; 88: 10303-11. doi: 10.1128/JVI.01341-14.

50. Mehic D, Bakiri L, Ghannadan M, Wagner EF, Tschachler E. Fos and jun proteins are specifically expressed during differentiation of human keratinocytes. J Invest Dermatol. 2005; 124: 212-20. doi: 10.1111/j.0022-202X.2004.23558.x.

51. Satoh T, Kidoya H, Naito H, Yamamoto M, Takemura N, Nakagawa K, Yoshioka Y, Morii E, Takakura N, Takeuchi $\mathrm{O}$, Akira S. Critical role of Trib1 in differentiation of tissueresident M2-like macrophages. Nature. 2013; 495: 524-8. doi: 10.1038/nature11930.

52. Iwamoto $\mathrm{S}$, Boonvisut $\mathrm{S}$, Makishima $\mathrm{S}$, Ishizuka $\mathrm{Y}$, Watanabe K, Nakayama K. The role of TRIB1 in lipid metabolism; from genetics to pathways. Biochem Soc Trans. 2015; 43: 1063-8. doi: 10.1042/BST20150094.

53. Fang F, Shangguan AJ, Kelly K, Wei J, Gruner K, Ye B, Wang W, Bhattacharyya S, Hinchcliff ME, Tourtellotte WG, Varga J. Early growth response 3 (Egr-3) is induced by transforming growth factor-beta and regulates fibrogenic 
responses. Am J Pathol. 2013; 183: 1197-208. doi: 10.1016/j.ajpath.2013.06.016.

54. Puthalakath H, Villunger A, O'Reilly LA, Beaumont JG, Coultas L, Cheney RE, Huang DC, Strasser A. Bmf: a proapoptotic $\mathrm{BH} 3$-only protein regulated by interaction with the myosin $\mathrm{V}$ actin motor complex, activated by anoikis. Science. 2001; 293: 1829-32. doi: 10.1126/ science. 1062257.

55. Barczyk M, Carracedo S, Gullberg D. Integrins. Cell Tissue Res. 2010; 339: 269-80. doi: 10.1007/s00441-009-0834-6.

56. Williams SJ, Wreschner DH, Tran M, Eyre HJ, Sutherland GR, McGuckin MA. Muc13, a novel human cell surface mucin expressed by epithelial and hemopoietic cells. J Biol Chem. 2001; 276: 18327-36. doi: 10.1074/jbc. M008850200.

57. Kudryavtseva AV, Krasnov GS, Dmitriev AA, Alekseev BY, Kardymon OL, Sadritdinova AF, Fedorova MS, Pokrovsky AV, Melnikova NV, Kaprin AD, Moskalev AA, Snezhkina AV. Mitochondrial dysfunction and oxidative stress in aging and cancer. Oncotarget. 2016; 7:44879-44905. doi: 10.18632/oncotarget.9821.

58. Bahar R, Hartmann $\mathrm{CH}$, Rodriguez KA, Denny $\mathrm{AD}$, Busuttil RA, Dolle ME, Calder RB, Chisholm GB, Pollock $\mathrm{BH}$, Klein CA, Vijg J. Increased cell-to-cell variation in gene expression in ageing mouse heart. Nature. 2006; 441: 1011-4. doi: 10.1038/nature04844.

59. Busuttil R, Bahar R, Vijg J. Genome dynamics and transcriptional deregulation in aging. Neuroscience. 2007; 145: 1341-7. doi: 10.1016/j.neuroscience.2006.09.060.

60. Tirone F. The gene PC3(TIS21/BTG2), prototype member of the PC3/BTG/TOB family: regulator in control of cell growth, differentiation, and DNA repair? J Cell Physiol. 2001; 187: 155-65. doi: 10.1002/jcp. 1062.

61. Zhavoronkov A, Buzdin AA, Garazha AV, Borisov NM, Moskalev AA. Signaling pathway cloud regulation for in silico screening and ranking of the potential geroprotective drugs. Front Genet. 2014; 5: 49. doi: 10.3389/ fgene.2014.00049.

62. Torre LA, Bray F, Siegel RL, Ferlay J, Lortet-Tieulent J, Jemal A. Global cancer statistics, 2012. CA: A Cancer Journal for Clinicians. 2015; 65: 87-108. doi: 10.3322/ caac. 21262 .

63. Kudryavtseva AV, Lipatova AV, Zaretsky AR, Moskalev AA, Fedorova MS, Rasskazova AS, Shibukhova GA, Snezhkina AV, Kaprin AD, Alekseev BY, Dmitriev AA, Krasnov GS. Important molecular genetic markers of colorectal cancer. Oncotarget. 2016; 7:53959-53983. doi: 10.18632/oncotarget.9796.

64. Moskalev A, Plyusnina E, Shaposhnikov M, Shilova L, Kazachenok A, Zhavoronkov A. The role of D-GADD45 in oxidative, thermal and genotoxic stress resistance. Cell Cycle. 2012; 11: 4222-41. doi: 10.4161/cc.22545.

65. Tamura RE, de Vasconcellos JF, Sarkar D, Libermann TA, Fisher PB, Zerbini LF. GADD45 proteins: central players in tumorigenesis. Curr Mol Med. 2012; 12: 634-51. doi: 10.2174/156652412800619978.

66. Ramachandran K, Gopisetty G, Gordian E, Navarro L, Hader C, Reis IM, Schulz WA, Singal R. Methylationmediated repression of GADD45alpha in prostate cancer and its role as a potential therapeutic target. Cancer Res. 2009; 69: 1527-35. doi: 10.1158/0008-5472.CAN-08-3609.

67. Moskalev AA, Smit-McBride Z, Shaposhnikov MV, Plyusnina EN, Zhavoronkov A, Budovsky A, Tacutu R, Fraifeld VE. Gadd45 proteins: relevance to aging, longevity and age-related pathologies. Ageing Research Reviews. 2012; 11: 51-66. doi: 10.1016/j.arr.2011.09.003.

68. Plyusnina EN, Shaposhnikov MV, Moskalev AA. Increase of Drosophila melanogaster lifespan due to D-GADD45 overexpression in the nervous system. Biogerontology. 2011; 12: 211-26. doi: 10.1007/s10522-010-9311-6.

69. Lawan A, A1-Harthi S, Cadalbert L, McCluskey AG, Shweash M, Grassia G, Grant A, Boyd M, Currie S, Plevin R. Deletion of the dual specific phosphatase-4 (DUSP4) gene reveals an essential non-redundant role for MAP kinase phosphatase-2 (MKP-2) in proliferation and cell survival. J Biol Chem. 2011; 286: 12933-43. doi: 10.1074/ jbc.M110.181370.

70. Domercq M, Alberdi E, Sanchez-Gomez MV, Ariz U, PerezSamartin A, Matute C. Dual-specific phosphatase-6 (Dusp6) and ERK mediate AMPA receptor-induced oligodendrocyte death. J Biol Chem. 2011; 286: 11825-36. doi: 10.1074/jbc. M110.153049.

71. Haag T, Richter AM, Schneider MB, Jimenez AP, Dammann RH. The dual specificity phosphatase 2 gene is hypermethylated in human cancer and regulated by epigenetic mechanisms. BMC Cancer. 2016; 16: 49. doi: 10.1186/s12885-016-2087-6.

72. Karakashev SV, Reginato MJ. Hypoxia/HIF1alpha induces lapatinib resistance in ERBB2-positive breast cancer cells via regulation of DUSP2. Oncotarget. 2015; 6: 1967-80. doi: 10.18632/oncotarget.2806.

73. Ueda K, Arakawa H, Nakamura Y. Dual-specificity phosphatase 5 (DUSP5) as a direct transcriptional target of tumor suppressor p53. Oncogene. 2003; 22: 5586-91. doi: 10.1038/sj.onc. 1206845.

74. Ma J, Yu X, Guo L, Lu SH. DUSP6, a tumor suppressor, is involved in differentiation and apoptosis in esophageal squamous cell carcinoma. Oncol Lett. 2013; 6: 1624-30. doi: 10.3892/ol.2013.1605. 